\title{
Projected Zika Virus Importation and Subsequent Ongoing Transmission after Travel to the 2016 Olympic and Paralympic Games - Country-Specific Assessment, July 2016
}

\author{
Ardath Grills, $\mathrm{PhD}^{1}$; Stephanie Morrison, DrPH${ }^{1,2}$; Bradley Nelson, $\mathrm{MS}^{1}$; Jennifer Miniota, MPH${ }^{3}$; Alexander Watts, $\mathrm{PhD}^{3}$; Martin S. Cetron, MD
}

\begin{abstract}
On July 13, 2016, this report was posted as an MMWR Early Release on the MMWR website (http://www.cdc.gov/mmwr).

Zika virus belongs to the genus Flavivirus of the family
\end{abstract} Flaviviridae; it is transmitted to humans primarily through the bite of an infected Aedes species mosquito (e.g., Ae. aegypti and Ae. albopictus) (1). Zika virus has been identified as a cause of congenital microcephaly and other serious brain defects (2). As of June 30, 2016, CDC had issued travel notices for 49 countries and U.S. territories across much of the Western hemisphere (3), including Brazil, where the 2016 Olympic and Paralympic Games (Games of the XXXI Olympiad, also known as Rio 2016; Games) will be hosted in Rio de Janeiro in August and September 2016. During the Games, mosquito-borne Zika virus transmission is expected to be low because August and September are winter months in Brazil, when cooler and drier weather typically reduces mosquito populations (4). CDC conducted a risk assessment to predict those countries susceptible to ongoing Zika virus transmission resulting from introduction by a single traveler to the Games. Whereas all countries are at risk for travel-associated importation of Zika virus, CDC estimated that 19 countries currently not reporting Zika outbreaks have the environmental conditions and population susceptibility to sustain mosquitoborne transmission of Zika virus if a case were imported from infection at the Games. For 15 of these 19 countries, travel to Rio de Janeiro during the Games is not estimated to increase substantially the level of risk above that incurred by the usual aviation travel baseline for these countries. The remaining four countries, Chad, Djibouti, Eritrea, and Yemen, are unique in that they do not have a substantial number of travelers to any country with local Zika virus transmission, except for anticipated travel to the Games. These four countries will be represented by a projected, combined total of 19 athletes (plus a projected delegation of about 60 persons), a tiny fraction of the 350,000-500,000 visitors expected at the Games.* Overall travel volume to the Games represents a very small fraction $(<0.25 \%)$ of the total estimated 2015 travel volume to

\footnotetext{
* According to the Brazilian Tourism Board (Embratur), approximately 350,000 500,000 international visitors are expected at the Games (http://www.embratur. gov.br/piembratur-new/opencms/salaImprensa/noticias/arquivos/Embratur_ aposta_que_Rio_2016_sera_a_melhor_Olimpiada.html).
}

Zika-affected countries, ${ }^{\dagger}$ highlighting the unlikely scenario that Zika importation would be solely attributable to travel to the Games. To prevent Zika virus infection and its complications among athletes and visitors to the Games and importation of Zika virus into countries that could sustain local transmission, pregnant women should not travel to the Games, mosquito bites should be avoided while traveling and for 3 weeks after returning home, and measures should be taken to prevent sexual transmission (Box).

To assess the country-specific risk for importation and sustained, local mosquito-borne transmission of Zika virus from travel to the Games, CDC constructed a stepwise model. The model began with the 206 countries and numbers of athletes planning to participate in the Games, as of June 30, 2016 (5). Each country was assessed on five criteria: 1) no active CDC travel notice (as of June 30,2016) reporting local Zika virus transmission (3); 2) modeled probability of Ae. aegypti presence, drawn from a data set of 20,000 observed occurrences during 1960-2014 (G) and fitted to climate norms for the months of August and September when travelers would return to their home country; 3 ) predicted dengue epidemic potential (7), such that the environmental and population conditions could support mosquito-borne disease spread from a single point of introduction; 4) lack of historic Zika virus circulation as evidenced by historic serosurveys, Zika virus detection, or exported Zika virus disease cases to exclude any country in which Zika virus might already be endemic (8); and 5) ranking countries by the estimated aviation travel passenger-journeys during August 2016 from Rio de Janeiro. Combined, the first four criteria estimate susceptibility to ongoing Zika transmission from introduction by a single traveler to the Games or to any other country with ongoing Zika virus transmission during August-September. The fifth criterion considers the probability that ongoing transmission could be the result of travel to the Games alone. In a stepwise manner, CDC successively excluded countries that did not meet the preceding criteria (Table 1).

\footnotetext{
$\dagger$ Calculated as a proportion using estimated foreign visitors to the Games (500,000 visitors) and the aviation travel for 2015 from all countries in the world to the 49 countries and U.S. territories with CDC Travel Notices, including journeys among countries with Zika transmission and domestic aviation journeys within Zika-affected countries (243,589,737 journeys).
} 
BOX. CDC prevention recommendations for athletes and visitors to Rio de Janeiro, and other areas where Zika virus is circulating

- Pregnant women should not travel to any area where Zika virus transmission is ongoing.

- Travelers should take protective measures, including use of insect repellent, to prevent mosquito bites both during travel and for 3 weeks after returning to their home country. Such measures include wearing long-sleeved shirts and long pants; staying in places with air conditioning and window and door screens to keep mosquitoes outside; sleeping under a mosquito bed net, and using insect repellents with active ingredients (e.g., DEET).

- Travelers should prevent possible sexual transmission while at the 2016 Olympic and Paralympic Games and after returning home by correctly using condoms every time they have sex or by abstaining from sex. Males should use condoms for at least 8 weeks after travel or, if symptomatic for Zika virus infection, for 6 months from the start of symptoms.

- After returning from a country with Zika virus transmission, men with pregnant partners should use condoms or not have sex for the duration of the pregnancy.

- Couples who want to try to get pregnant after attending the Olympic and Paralympic Games should wait at least 8 weeks, and 6 months if the male partner has symptomatic Zika virus infection.

Research based on the previous four summer Olympics has indicated that travel during the Olympics typically does not exceed baseline travel volume patterns to the host city (Kamran Khan, Li Ka Shing Knowledge Institute, St. Michael's Hospital, Toronto, Canada, personal communication, June 2016). Therefore, for most countries, the number of passengerjourneys from Rio de Janeiro during August 2016 was assumed to be approximately the same as the number of journeys occurring during August 2015. Modeled data were used to estimate the number of passenger-journeys originating from Rio de Janeiro during August $2015 .{ }^{\S}$ For countries without documented passenger-journeys from Rio de Janeiro in August 2015, the estimated Olympic delegation size was used as a proxy for travel volume during August 2016.** Delegation size was determined by viewing video footage of the Parade of Nations from the London 2012 Olympics Opening Ceremony and comparing the number of persons observed with the known number of athletes; this is likely an underestimation

\footnotetext{
$\$$ https://www.diio.net.

Delegation is defined as athletes and other official attendees from a country, such as coaches, referees, officials, etc.

** https://www.rio2016.com/en/athletes.
}

given that some delegates might not participate in the parade (5). Finally, CDC calculated the estimated aviation travel from Rio de Janeiro during August 2016 as the proportion of each country's total travel to all Zika-affected countries during 2015. ${ }^{\dagger \dagger}$ For example, there were 36,923,504 passengerjourneys to the United States from all Zika-affected countries and U.S. territories in 2015 and 38,798 journeys from Rio de Janeiro during August 2015; thus, the proportion of estimated U.S. travel from Rio de Janeiro for the Games, relative to that of all Zika-affected countries is $0.11 \%$. CDC assumed that any country whose estimated proportion of travel to Rio de Janeiro among all travel to Zika transmission areas exceeded $5 \%$ was at risk for ongoing transmission of Zika attributable to the Games.

Among the 206 countries competing in the Games, 39 have $\mathrm{CDC}$ travel notices indicating ongoing Zika virus outbreaks or epidemics (Table 1). Among the remaining 167 countries, 148 were not considered to be at risk for the following reasons: 74 did not have a predicted presence of Ae. aegypti in AugustSeptember, 51 did not also have a predicted high dengue epidemic potential, and 23 also had evidence of previous Zika virus transmission. Thus, 19 countries currently not reporting Zika outbreaks that are participating in the Games met all the risk criteria for susceptibility to ongoing Zika transmission from introduction by a single traveler to the Olympics. For 15 of these countries, estimated aviation travel from Rio de Janeiro in August 2016 compared with total aviation travel from all countries with local Zika virus transmission in 2015 was $0.01 \%-3.25 \%$ (Table 2). Four countries (Chad, Djibouti, Eritrea, and Yemen) were estimated to have $>19 \%$ of travel from Rio de Janeiro in August 2016 compared with the overall aviation travel from all countries with local Zika transmission.

\section{Discussion}

This risk assessment reflects an unlikely scenario, given that it will be winter in Rio de Janeiro during the Games and mosquito-borne transmission of Zika virus is predicted to be low. Nineteen countries participating in the Games have no evidence of ongoing or previous Zika virus transmission but do have the environmental and population conditions that could support ongoing mosquito-borne Zika virus transmission after introduction from a single traveler after the Games. For 15 of the countries, travel to Rio de Janeiro during the Games is not estimated to increase substantially the level of risk above that incurred by the usual aviation travel baseline for these countries. Chad, Djibouti, Eritrea, and Yemen have

\footnotetext{
†† For countries lacking total aviation travel from Rio de Janeiro in August 2015, estimated size of delegation was added to the aviation travel from all Zikaaffected countries in 2015.
} 
TABLE 1. Iterative analytic process for estimating risk for Zika virus importation and subsequent ongoing transmission after the 2016 Olympic and Paralympic Games — 206 participating countries, 2016

\begin{tabular}{|c|c|c|c|}
\hline \multirow{2}{*}{\multicolumn{2}{|c|}{ Analytic criteria }} & \multicolumn{2}{|c|}{ No. countries } \\
\hline & & $\begin{array}{l}\text { Not meeting } \\
\text { criteria }\end{array}$ & $\begin{array}{l}\text { Remaining in } \\
\text { iterative analysis* }\end{array}$ \\
\hline 1 & Without CDC Zika travel notice $^{\dagger}$ & 39 & 167 \\
\hline 2 & Aedes aegypti in August-September $§$ & 74 & 93 \\
\hline 3 & Predicted high dengue epidemic potential" & 51 & 42 \\
\hline 4 & No evidence of past Zika virus transmission** & 23 & 19 \\
\hline 5 & Proportion of travel attributable to Games out of all travel to Zika transmission areas $\geq 5 \%{ }^{\dagger \dagger}$ & 15 & 4 \\
\hline
\end{tabular}

Abbreviation: Olympic and Paralympic Games (Games) = Games of the XXXI Olympiad, Rio 2016.

* For each step of the analysis, countries were removed iteratively. Thus, for example, among the 206 countries participating in the Games, 39 countries did not meet criteria 1 and were removed, leaving 167 countries; for criteria 2, 93 countries met both criteria 1 and $2(167-74=93)$.

${ }^{\dagger}$ Forty-nine countries and U.S. territories currently have Zika travel notices (https://wwwnc.cdc.gov/travel/page/zika-travel-information). Some areas with notices are not competing in the Games (as of June 30, 2016), including Anguilla, Bonaire, Curacao, Guadeloupe, Guiana, Martinique, New Caledonia, Saint Barthelemy, Saint Martin, and Sint Maarten.

$\S$ https://elifesciences.org/content/4/e08347.

I http://www.nature.com/nature/journal/v496/n7446/full/nature12060.html.

** http://cmr.asm.org/content/29/3/487.abstract.

${ }^{+\dagger}$ https://www.diio.net.

TABLE 2. Participating countries currently not reporting Zika outbreaks $(n=19)$ that met risk criteria for Zika virus importation and subsequent ongoing transmission attributed to travel to the Olympic and Paralympic Games, ranked by aviation travel volume* from Rio de Janeiro, Brazil - August 2016

\begin{tabular}{|c|c|c|c|c|}
\hline Country & $\begin{array}{c}\text { Total aviation travel from Rio de } \\
\text { Janeiro in August } 2015 \\
\text { (no. passenger-journeys) }\end{array}$ & $\begin{array}{l}\text { No. of athletes for } \\
2016 \text { Games }^{\dagger}\end{array}$ & $\begin{array}{c}\text { Estimated size of Olympic } \\
\text { delegation for countries } \\
\text { without aviation travel from } \\
\text { Rio de Janeiro in August } 2015 \\
\text { (no. persons) }\end{array}$ & $\begin{array}{c}\text { Aviation travel from all } \\
\text { Zika-affected countries in } 2015^{\S} \\
\text { No. passengers } \\
\text { (\% travel attributable to } \\
\text { Rio de Janeiro") }\end{array}$ \\
\hline Angola & 2,841 & 21 & NA & $87,549(3.25)$ \\
\hline China & 1,201 & 379 & NA & $308,238(0.39)$ \\
\hline Hong Kong ${ }^{* *}$ & 229 & 32 & NA & $108,215(0.21)$ \\
\hline Sao Tome and Principe & 104 & 2 & NA & $4,732(2.20)$ \\
\hline Oman & 70 & 3 & NA & $2,300(3.04)$ \\
\hline Saudi Arabia & 46 & 8 & NA & $7,688(0.60)$ \\
\hline Congo & 22 & 6 & NA & $2,023(1.09)$ \\
\hline Myanmar & 15 & 1 & NA & $733(2.05)$ \\
\hline Antigua and Barbuda & 10 & 3 & NA & $61,312(0.02)$ \\
\hline Cayman Islands & 10 & 3 & NA & $66,859(0.01)$ \\
\hline Ghana & 10 & 6 & NA & $2,498(0.40)$ \\
\hline Rwanda & 1 & 5 & - & $281(0.36)$ \\
\hline Eritrea & 0 & 9 & 27 & $27(100)$ \\
\hline Yemen & 0 & $4^{+\dagger}$ & 12 & $13(92)$ \\
\hline Djibouti & 0 & 4 & 12 & 62 (19.35) \\
\hline The Gambia & 0 & 3 & 9 & $1,198(0.75)$ \\
\hline Chad & 0 & $2^{\dagger \dagger}$ & 6 & 19(31.6) \\
\hline Mauritania & 0 & $2^{\dagger \dagger}$ & 6 & 201 (2.99) \\
\hline Sudan & 0 & 1 & 3 & 153 (1.96) \\
\hline
\end{tabular}

Abbreviation: NA = not applicable because countries had aviation travel to Rio de Janeiro; Olympic and Paralympic Games = Games of the XXXI Olympiad, Rio 2016.

${ }^{*}$ https://www.diio.net.

† http://www.sports-reference.com/olympics.

$\S$ For countries without total aviation travel from Rio de Janeiro in August, 2015, estimated size of delegation was added to aviation travel from all Zika-affected countries in 2015.

9 Calculated as aviation from Rio de Janeiro in August 2015 divided by aviation travel from all Zika-affected countries in 2015. For countries with no documented aviation passenger-journeys in August 2015, the estimated Olympic delegation size was substituted as the numerator in place of passenger-journeys.

** Hong Kong is a separate member of the International Olympic Committee and competes independently during the Olympics.

t+ Chad, Mauritania, and Yemen had not qualified athletes for the 2016 Games as of June 30, 2016. Numbers from 2012 Olympics are used for athlete and delegation. 
an additional, unique factor: apart from projected travel to the Games, these countries do not have substantial travel to any country with local Zika virus transmission. With the exception of these four countries, the Games do not pose a unique or substantive risk for mosquito-borne transmission of Zika virus in excess of that posed by non-Games travel.

To create a model based on "worst-case scenarios," CDC identified five assumptions. First, CDC assumed that Zika transmission would be ongoing during the winter months of August and September in Rio de Janeiro. Historically, winter months are low season for mosquito-borne disease transmission in Rio de Janeiro (4). Second, it was assumed that preventive measures, such as wearing long sleeves and pants or using insect repellent, would not be used or would be ineffective, and that all visitors would have an equal risk for exposure to Zika virus. Third, visitors who were infected were assumed to be viremic upon return from the Games. Fourth, infected visitors were assumed to return immediately to their home country with no extended stays in other countries. Fifth, it was assumed that visitors would not employ precautions to prevent mosquito bites upon return to their home country.

The findings in this report are subject to at least five limitations. First, the aviation travel data set comprised modeled estimates of passenger-journeys from 2015, not actual counts of travelers, and aviation travel data might have changed in 2016. Second, delegation sizes were estimated using a simple formula based on the projected numbers of athletes. However, the planned participating countries and numbers of athletes reflect data available as of June 30, 2016 (5) when Olympic qualifying events were ongoing and the numbers of athletes had not been finalized. Chad, Mauritania, and Yemen had not completed qualifications, so the number of athletes from the 2012 London Games was used to estimate the number of athletes for the 2016 Rio de Janeiro Games. Third, analyses were completed considering only the primary Zika virus vector, Ae. Aegypti, and not Ae. Albopictus, which is less commonly associated with transmission; however, this did not affect the results, because none of the countries where Ae. albopictus but not Ae. aegypti is present met all four risk criteria. Fourth, assessment included all estimated passenger-journeys from Rio de Janeiro in August 2016, although many of these passenger journeys might be unrelated to the Olympics. Finally, the analysis does not estimate actual risk, which would be expected to be related to travel volume (and therefore low for countries with low travel volume), but instead estimates proportionate changes in risk that could occur because of travel during the Games.

Global travel has resulted in spread of Zika virus across much of the Western Hemisphere (9). Substantial and continuous

\section{Summary \\ What is already known about this topic?}

High travel volume globally has disseminated Zika virus broadly across much of the Region of the Americas since May 2015, highlighting the major role of globalization in rapidly spreading this emerging virus.

What is added by this report?

All countries are at risk for travel-associated importation of Zika virus. CDC identified 19 countries currently not reporting Zika outbreaks but with environmental conditions and population susceptibility that could sustain mosquito-borne transmission of Zika virus during August-September. Among these, Chad, Djibouti, Eritrea, and Yemen have risk uniquely attributable to their travel related to the 2016 Olympic and Paralympic Games (Games), because these four countries do not have substantial non-Games travel to any countries with local Zika virus transmission.

What are the implications for public health practice?

With the exception of four countries, attendance at the Games does not pose a unique or substantive risk for mosquito-borne transmission of Zika virus in excess of that posed by non-Games travel. Efforts to enhance global health security to prevent, detect, and respond to Zika virus, as well as other emerging infections, require a sustained international commitment at all levels of government, the private sector, and civil society.

travel has occurred between most of the countries participating in the Games and the 49 countries or U.S. territories with CDC Zika Travel Notices. Global connectivity creates a pervasive risk for importation of Zika virus by travelers from areas with local transmission. These findings support implementation of public health interventions that increase ongoing readiness and response capabilities to prevent Zika virus transmission, including educating travelers regarding prevention of infection and transmission. CDC recommends that pregnant women not travel to any area with ongoing Zika virus transmission. Pregnant women with male partners who travel to Zika transmission areas should correctly use condoms every time they have sex or abstain from sex during pregnancy. Athletes and visitors to Rio de Janeiro and other Zika transmission areas should follow precautions to prevent exposure to the virus. Specifically, all delegation members and visitors should take rigorous steps to reduce the likelihood of mosquito bites (e.g. use insect repellent) both during the Games and within the three weeks after they return to their home country from an area with ongoing Zika transmission (Box). Efforts to enhance global health security to prevent, detect, and respond to Zika virus, as well as other emerging infections, require a sustained international commitment at all levels of government, the private sector, and civil society. 


\section{Acknowledgments}

Kamran Khan, Carmen Huber, Sonya Karamchandani, Joanna Vass, Li Ka Shing Knowledge Institute, St. Michael's Hospital, Toronto, Canada; Abbey Wojno, Jenique Meekins, Yescenia Wilkins, Division of Global Migration and Quarantine, CDC.

${ }^{1}$ Division of Global Migration and Quarantine, CDC; ${ }^{2}$ Eagle Medical Services, Atlanta, Georgia; ${ }^{3} \mathrm{Li}$ Ka Shing Knowledge Institute, St. Michael's Hospital, Toronto, Canada.

Corresponding author: Martin Cetron, mcetron@cdc.gov, 770-488-7100.

\section{References}

1. Chouin-Carneiro T, Vega-Rua A, Vazeille M, et al. Differential susceptibilities of Aedes aegypti and Aedes albopictus from the Americas to Zika virus. PLoS Negl Trop Dis 2016;10:e0004543. http://dx.doi. org/10.1371/journal.pntd.0004543

2. Rasmussen SA, Jamieson DJ, Honein MA, Petersen LR. Zika virus and birth defects-reviewing the evidence for causality. N Engl J Med 2016;374:1981-7. http://dx.doi.org/10.1056/NEJMsr1604338
3. CDC. Traveler's health. Atlanta, GA: US Department of Health and Human Services; 2016. http://wwwnc.cdc.gov/travel/notices

4. World Health Organization. Zika virus and the Olympic and Paralympic Games 2016. Geneva, Switzerland: World Health Organization; 2016. http://www.who.int/mediacentre/news/statements/2016/zika-olympics/en/

5. Sports Reference. Olympic sports. Philadelphia, PA: Sports Reference LLC; 2016. http://www.sports-reference.com/olympics/

6. Kraemer MUG, Sinka ME, Duda KA, et al. The global distribution of the arbovirus vectors Aedes aegypti and Ae. albopictus. eLife 2015;4:e08347. http://dx.doi.org/10.7554/eLife.08347

7. Bhatt S, Gething PW, Brady OJ, et al. The global distribution and burden of dengue. Nature 2013;496:504-7. http://dx.doi.org/10.1038/ nature 12060

8. Musso D, Gubler DJ. Zika virus. Clin Microbiol Rev 2016;29:487K524.

9. Pan American Health Organization. Geographic distribution of confirmed autochthonous cases of Zika virus (vector-borne transmission) in countries and territories of the Americas, 2015-2016. Geneva, Switzerland: World Health Organization, Pan American Health Organization, 2016. http:// ais.paho.org/phip/viz/ed_zika_countrymap.asp 